\title{
A nonlinear concrete damaged plasticity model for simulation reinforced concrete structures using ABAQUS
}

\author{
Thanh Cuong-Le*, Hoang-Le Minh, Thanh Sang-To \\ Faculty of Civil Engineering, Ho Chi Minh City Open University, Ho Chi Minh City, Viet Nam \\ cuong.lt@ou.edu.vn, hoang.lm@ou.edu.vn,sang.tt@ou.edu.vn
}

\begin{abstract}
The reinforced concrete structure is typical and widely used in many fields. The behavior of concrete is nonlinear and complex. Especially, when cracks/crushings occurred in softening phase. Thus, It is important to find a damaged model of concrete with high reliability in the numerical simulation. The nonlinear behavior of concrete is the most feature used in the simulation. This characteristic is expressed through the parameters defining the yield surface, the flow potential, and the nonlinear relationship of stressstrain in the cases of tension and compression. This paper introduces a damaged concrete model that applies to the simulation of reinforced concrete structures. The reinforced concrete beam and flat slab are selected as examples to evaluate the reliability of the model presented. Through the results achieved, the model used in this paper shows high reliability and can be used to simulate more complex reinforced concrete structures.
\end{abstract}

KEYwORDS. Nonlinear behavior; Concrete material; Numerical simulation; Concrete damaged plasticity.

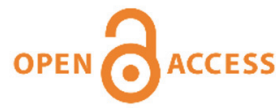

Citation: Cuong-Le, T., Le-Minh, H., SangTo, T., A nonlinear concrete damaged plasticity model for simulation reinforced concrete structures using ABAQUS, Frattura ed Integrità Strutturale, 59 (2022) 232-242.

Received: 12.09.2021

Accepted: 23.09.2021

Published: 01.01.2022

Copyright: (C) 2022 This is an open access article under the terms of the CC-BY 4.0, which permits unrestricted use, distribution, and reproduction in any medium, provided the original author and source are credited.

\section{INTRODUCTION}

$\mathrm{B}$ ecause of the complicated nonlinear behavior of concrete material. There are many theories about the damaged model in a finite element method (FEM) analysis reported in the literature. Among the damaged models, the concrete damaged plasticity (CDP) model is considered the most reliable use in simulation. Based on this model, by using many other techniques, many damaged models have been proposed. Most improved techniques are based on developing a new stress-strain relationship in both compression and tension or proposing a novel function to calculate damaged parameters in compression dc and tension ( $d t)$. Lubliner et al. [1] was proposed a novel constitutive model lied on plasticity theory for the non-linear analysis of concrete. A new yield criterion was presented which accounts for both elastic and plastic stiffness degradations effects. Comparing results between numerical simulation and experimental methods showed that the model responded well to applications. Carol et al. [2] was presented as a formulation for tensile damage. One of the important advantages of the model is that closed-form solutions are possible for some loading cases. Damaged models which are based on presenting a novel curve of stress-strain in three dimensions stress can find in reports of. Ahmed et al. [3]. were proposed a damaged model based on the novel stress accounting for damaged shear. The new stress makes further decompose tensile and compressive parts into pure biaxial shear and pure tensile/compressive biaxial stresses. The theory of Lubliner theory [1] was employed to develop a new method to modify 
the damaged concrete model by Lee et al. [4]. Thus, this proposed model was accounted for confinement having a uniform and non-uniform conditions. Jason et al. [5] introduced the new function to calculate the damaged elastic-plastic. This model has overcome the limitations of pure elastic-plastic damage in the case un-loading phase. Grassl et al. [6] were used the combination of damage mechanics and plasticity flow to investigate the concrete structure under dynamic loading conditions, etc. In this paper, the concrete damaged plasticity model (CDP) in combination with the tensile damage variable $(d t)$ and compressive damage variable $(d c)$ were followed by Birtel and Mark [7]. This model is employed to simulate the test of a reinforced concrete beam namely C3 in tests of Vecchio và Shim (2004) [8] and a reinforced concrete slab in test of Genikomsou and Polak [9] for reliable consideration.

\section{A DAMAGED MODEL PRESENTED FOR CONCRETE}

\section{Material parameters for the yield function and plastic flow potential}

$\checkmark$ he damaged concrete plasticity model (CDP) is employed in the ABAQUS manual. This model was improved by Lee and Fenves [4]. The model CDP based on that definition the yield function of concrete shown in Fig. 1 and the parameters of flow potential and yield surface given in Tab. 1 . Where $\sigma_{b 0} / \sigma_{c 0}$ is the ratio between the strength of biaxial and uniaxial in compression. Kc is the ratio between the magnitudes of deviatoric stress in uniaxial tension and compression.

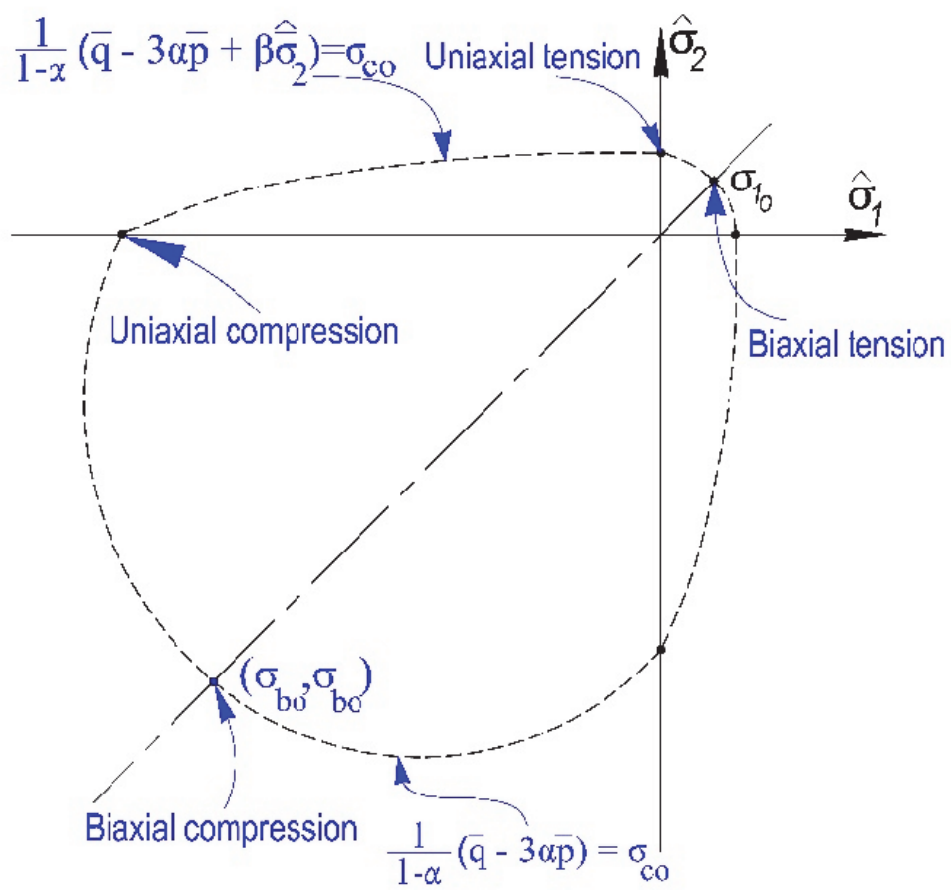

Figure 1: Concrete yield surface

\begin{tabular}{cccc}
\hline Dilation angle & Eccentricity $(\varepsilon)$ & $\sigma_{b 0} / \sigma_{c 0}$ & $K_{c}$ \\
$30^{\circ} \sim 40^{0}$ & 0.1 & 1.16 & 0.667 \\
\hline
\end{tabular}

Table 1: The material parameters in CDP model.

Compressive and tensile behavior

Behavior in compression

Uniaxial loading conditions in compression includes 3 phases shown in Fig. 2. The details of phases are described below: 
Phase 1: in this phase, the relationship of stress-strain is denoted linear given in Eqn. (1). At the end of this phase registered $\sigma_{c}=0.4 f_{c m}$ according to EC2.

$$
\sigma_{c}^{1}=E_{0} \varepsilon_{c}
$$

Phase 2: when the compressive stress is achieved $\sigma_{c}=0.4 f_{c m}$, cracks begin to appear Accordingly, the relationship of stress-strain of concrete in this phase is nonlinear behavior given in Eqn. (2)

$$
\sigma_{c}^{2}=\frac{E_{c i} \frac{\varepsilon_{c}}{f_{c m}}-\left(\frac{\varepsilon_{c}}{\varepsilon_{c 1}}\right)^{2}}{1+\left(E_{c i} \frac{\varepsilon_{c 1}}{f_{c m}}-2\right) \frac{\varepsilon_{c}}{\varepsilon_{c 1}}} f_{c m}
$$

where $E_{c i}$ is the modulus of elasticity of concrete.

Phase 3: The behavior of concrete in this phase is softening and determined based on the theory which is proposed by Kratzig and Polling (2004), this model is suitable for numerical analysis because the model depends on the length of mesh elements $l_{e q}$. Phase 3 is expressed in Eqns. (3-4).

$$
\begin{aligned}
\sigma_{c}^{3} & =\left(\frac{2+\gamma_{c} f_{c m} \varepsilon_{c 1}}{2 f_{c m}}-\gamma_{c} \varepsilon_{c}+\frac{\varepsilon_{c}^{2} \gamma_{c}}{2 \varepsilon_{c 1}}\right)^{-1} \\
\gamma_{c} & =\frac{\pi^{2} f_{c m} \varepsilon_{c 1}}{2\left[\frac{G_{c b}}{l_{e q}}-0.5 f_{c m}\left(\varepsilon_{c 1}(1-b)+b \frac{f_{c m}}{E_{0}}\right)\right]^{2}} ; \quad b=\frac{\varepsilon_{c}^{p l}}{\varepsilon_{c}^{i n}}
\end{aligned}
$$

where $G_{c h}$ denotes crushing energy, $\varepsilon_{c}^{p l}$ and $\varepsilon_{c}^{i n}$ are plastic strain and inelastic strain, respectively.

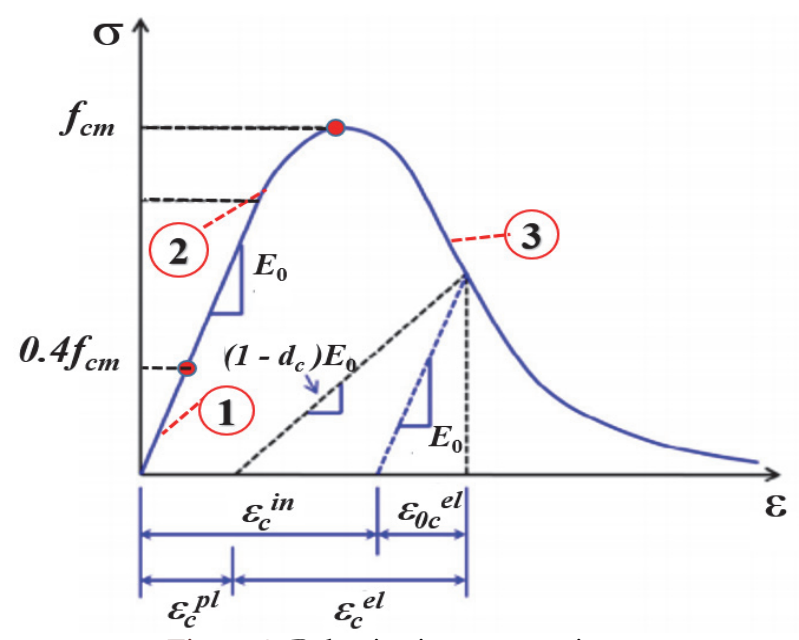

Figure 2: Behavior in compression.

\section{Behavior in tension}

The tensile nonlinear behavior of concrete is a curve showing the stress-crack opening relationship proposed by Hordijk. The characteristic of this curve is that it does not depend on the element meshing in the FEM model. The formulation of this relationship is given in Eqn. (5). 


$$
\frac{\sigma_{t}(w)}{f_{t m}}=\left[1+\left(c_{1} \frac{w}{w_{c}}\right)^{3}\right] e^{-c_{2} \frac{w}{w_{c}}}-\frac{w}{w_{c}}\left(1+c_{1}^{3}\right) e^{-c 2}
$$

where $c_{1}=3, c_{2}=6.93$ and wc is the critical crack opening which can be considered as the fracture crack opening given in Eqn. (6).

$$
w_{c}=5.14 \frac{G_{F}}{f_{t m}}
$$

Based on the curve of stress-crack opening relationship, it can be obtained a new curve having the feature of stress-strain through Eqn. (7). Thus, the strain $\varepsilon_{t}$ at tensile strength $\varepsilon_{t m}$ can be evaluated from crack opening. Where $l_{e q}$ can consider as a length of element (meshed size). After this assumption, the stress-strain curve relationship given in Fig. 3.

$$
\varepsilon_{t}=\varepsilon_{t m}+\frac{w}{l_{e q}}
$$

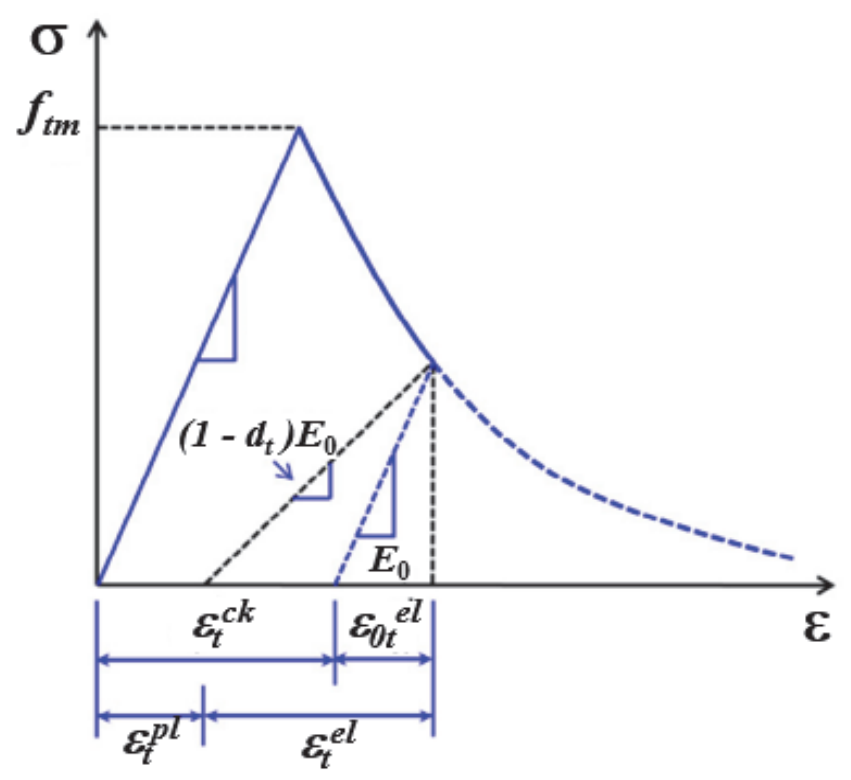

Figure 3: Behavior in tension.

Compressive damage and tension damaged component

Compression damage variable $(d c)$

This parameter is used to specify compressive stiffness degradation damage, $d_{c}$ is determined through plastic strain $\varepsilon_{c}^{p l}$ and a using a constant factor $b_{c}$ with $0<b_{c} \leq 1$.

$$
d_{c}=1-\frac{\sigma_{c} E_{c}^{-1}}{\varepsilon_{c}^{p l}\left(1 / b_{c}-1\right)+\sigma_{c} E_{c}^{-1}}
$$

In this paper, assumption $b_{c}=0.7$ to evaluate the parameter $d_{c}$. Fig. 4 illustrates the relationship between compressive damage parameter and inelastic strain with concrete having strength $f_{c m}=35$ calculated in Eqn. (8). 


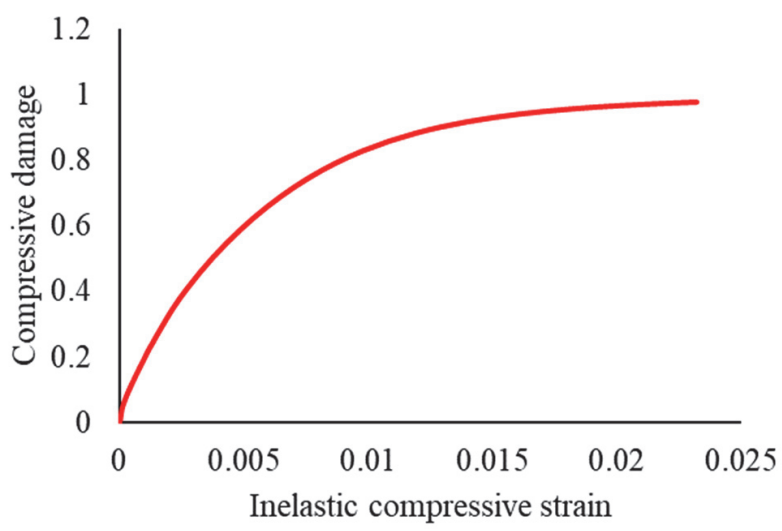

Figure 4: The curve of compressive damage parameter and inelastic strain

Tension damage variable $(d t)$

Similar to the compression damage variable $d_{c}$, the damaged parameter in tension $d_{t}$ depends on $\varepsilon_{t}^{p l}$ and an experimentally determined parameter $b_{t}=0.1$. So, unloading is assumed to return almost back to the origin and to leave only a small residual strain.

$$
d_{t}=1-\frac{\sigma_{c} E_{c}^{-1}}{\varepsilon_{c}^{p l}\left(1 / b_{t}-1\right)+\sigma_{t} E_{c}^{-1}}
$$

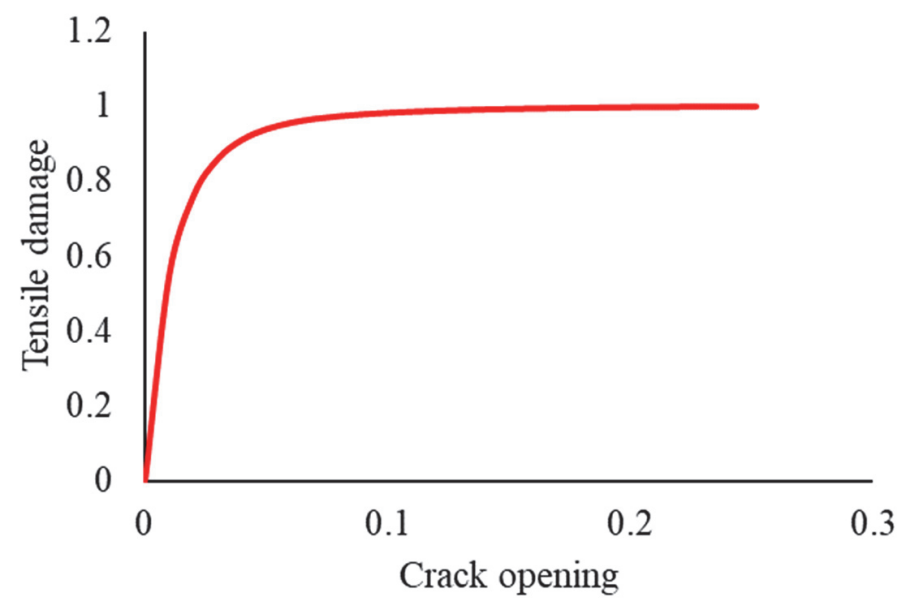

Figure 5: The curve of compressive damage parameter and crack opening.

\section{APPLICATION FOR SIMULATION OF A REINFORCE CONCRETE BEAM}

A beam namely C3 is selected as reported by Vecchio và Shim (2004) [8]. The geometry and details of beam C3 are shown in Fig. 6. The beam has a section; $152 \mathrm{~mm}$ width and $552 \mathrm{~mm}$ height. The length of the beam is $6400 \mathrm{~mm}$. Rebars at the bottom layer arrange (2M30+2M25) and at the top layer is (3M10). Experimental geometry and details of C3 beam are shown in Fig. 6. The material characteristics of the C3 beam are given in Tab. 2.

Numerical simulation was established using ABAQUS software. In detail, the beam uses solid element type C3D8R with 1 point of Gaussian integration, rebar uses T2D3 element which is only under tension and compression conditions, Interaction between rebar and concrete using "Embedded" algorithm. This method allows a node or group nodes of rebar to be constrained to the kinetic boundary conditions with the nodes in the concrete elements. In the simulation C3 beam of Vecchio and Shim (2004) [10], the rebar and the concrete have meshed with the same element size (40mm). The 
interaction between the rigid steel plate and the concrete uses the "Tie". The progress in the simulation is shown in Fig. 7. A comparison of the displacement which is arranged at the middle beam between the simulation and data obtained from the experiment is given in Fig. 8. The results in Fig. 8 show that the damaged nonlinear model presented satisfies the beam stiffness degradation. Simulation result at the complete failure of the beam registered the loading having $266 \mathrm{kN}$ compared with the test loading having $267 \mathrm{kN}$.

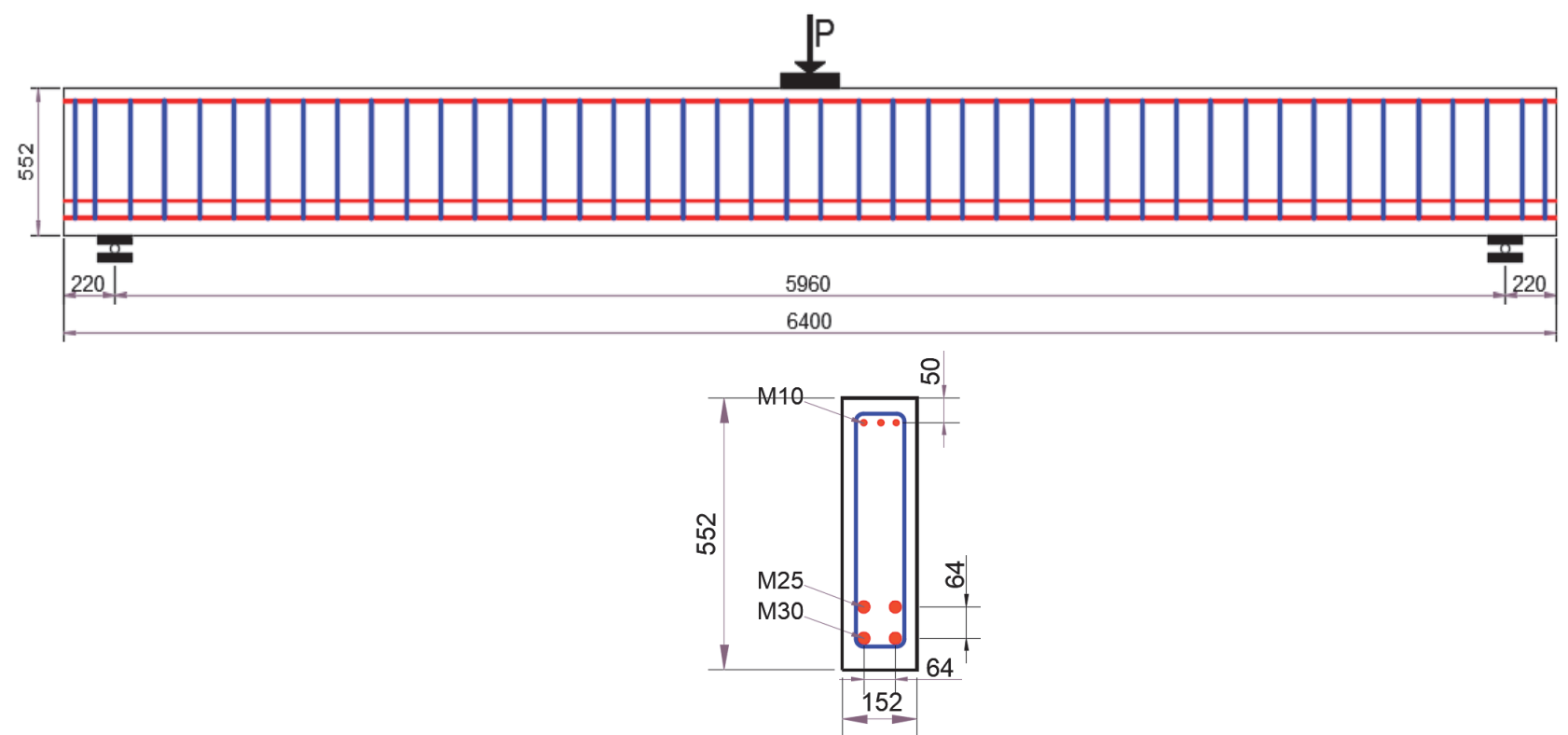

Figure 6: Elevations and cross-sections of C3 beam.

\begin{tabular}{|c|c|c|c|}
\hline \multicolumn{4}{|l|}{ Concrete } \\
\hline Avarage compressive strength & $\mathrm{f}_{\mathrm{cm}}$ & 43.5 & $\mathrm{~N} / \mathrm{mm}^{2}$ \\
\hline Modulus of elasticity & $\mathrm{E}_{\mathrm{ci}}$ & 34300 & $\mathrm{~N} / \mathrm{mm}^{2}$ \\
\hline Tensile strength & $\mathrm{F}_{\mathrm{tm}}$ & 3.13 & $\mathrm{~N} / \mathrm{mm}^{2}$ \\
\hline \multicolumn{4}{|l|}{ Rebar-M10 } \\
\hline Diameter & $\phi$ & 11.3 & $\mathrm{~mm}$ \\
\hline Modulus of elasticity & $\mathrm{E}$ & 200000 & $\mathrm{~N} / \mathrm{mm}^{2}$ \\
\hline Yield strength & $\mathrm{f}_{\mathrm{v}}$ & 315 & $\mathrm{~N} / \mathrm{mm}^{2}$ \\
\hline Ultimate tensile strength & $f_{u}$ & 460 & $\mathrm{~N} / \mathrm{mm}^{2}$ \\
\hline \multicolumn{4}{|l|}{ Rebar- M25 } \\
\hline Diameter & $\phi$ & 25.2 & $\mathrm{~mm}$ \\
\hline Modulus of elasticity & $\mathrm{E}$ & 200000 & $\mathrm{~N} / \mathrm{mm}^{2}$ \\
\hline Yield strength & $f_{y}$ & 445 & $\mathrm{~N} / \mathrm{mm}^{2}$ \\
\hline Ultimate tensile strength & $\mathrm{f}_{\mathrm{u}}$ & 680 & $\mathrm{~N} / \mathrm{mm}^{2}$ \\
\hline \multicolumn{4}{|l|}{ Rebar- M30 } \\
\hline Diameter & $\phi$ & 29.9 & $\mathrm{~mm}$ \\
\hline Modulus of elasticity & $\mathrm{E}$ & 200000 & $\mathrm{~N} / \mathrm{mm}^{2}$ \\
\hline Yield strength & $f_{y}$ & 436 & $\mathrm{~N} / \mathrm{mm}^{2}$ \\
\hline Ultimate tensile strength & $\mathrm{f}_{\mathrm{u}}$ & 700 & $\mathrm{~N} / \mathrm{mm}^{2}$ \\
\hline \multicolumn{4}{|l|}{ Rebar- D4 } \\
\hline Diameter & $\phi$ & 3.7 & $\mathrm{~mm}$ \\
\hline Modulus of elasticity & $\mathrm{E}$ & 200000 & $\mathrm{~N} / \mathrm{mm}^{2}$ \\
\hline Yield strength & $\mathrm{f}_{\mathrm{y}}$ & 600 & $\mathrm{~N} / \mathrm{mm}^{2}$ \\
\hline Ultimate tensile strength & $f_{u}$ & 651 & $\mathrm{~N} / \mathrm{mm}^{2}$ \\
\hline
\end{tabular}

Table 2: Material characteristics of the C3 beam. 

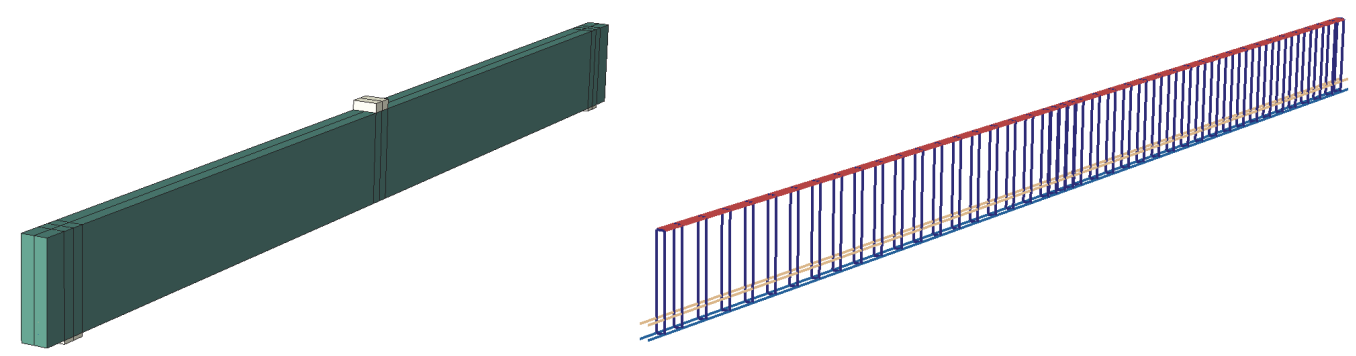

Figure 7: Simulation C3 beam using ABAQUS.

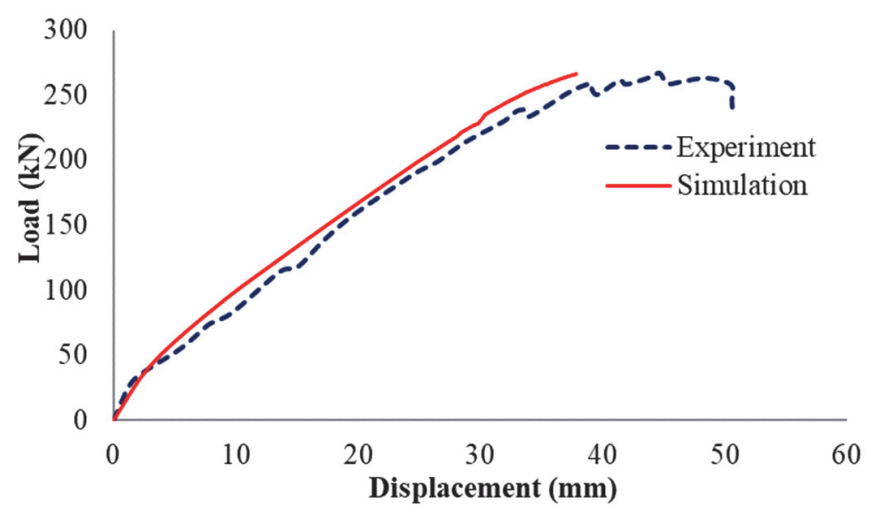

Figure 8: Comparison of the displacement between simulation and experiment.
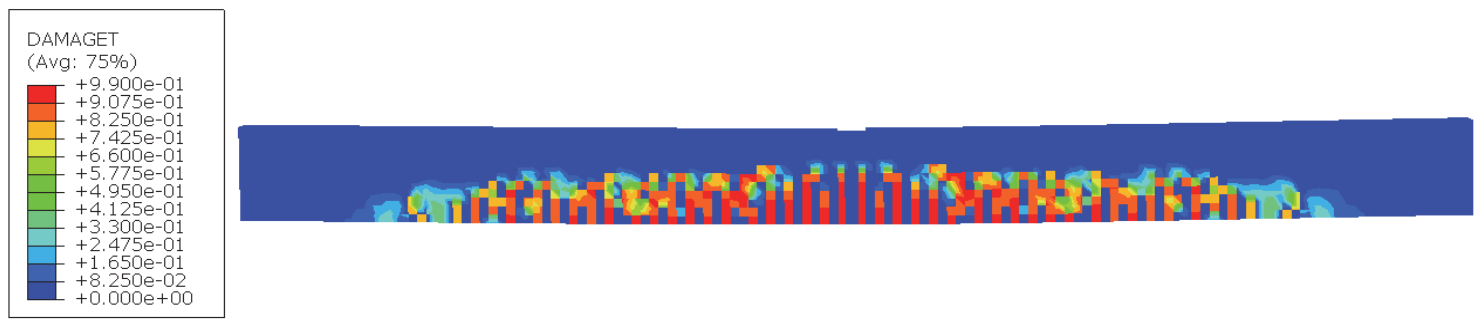

Figure 9: Cracking pattern in simulation.

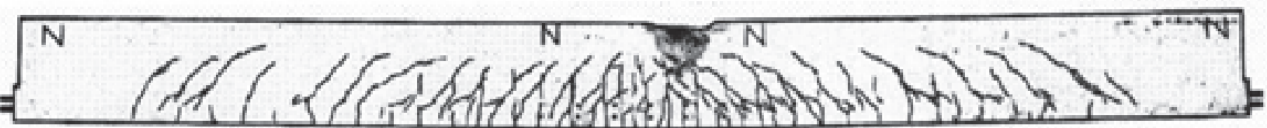

Figure 10: Damaged C3 beam in an experiment.
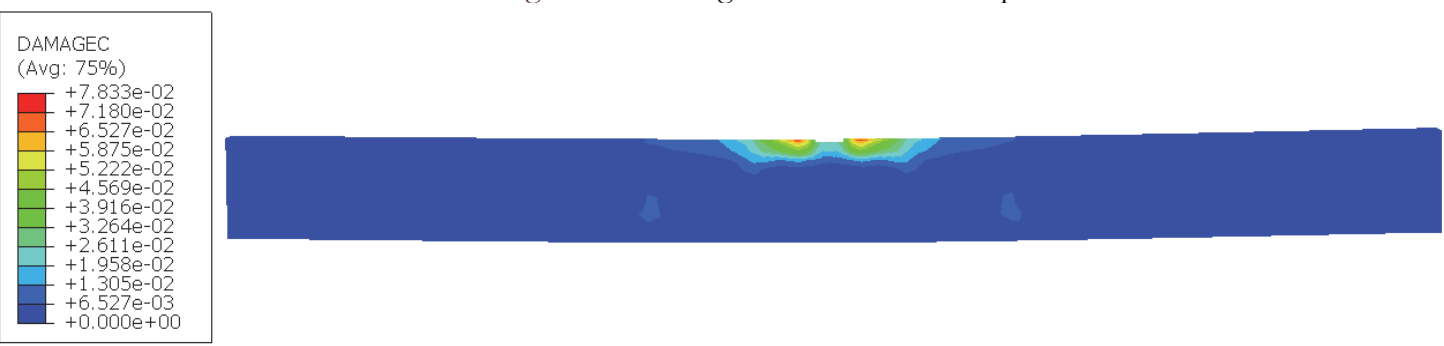

Figure 11: Crushing pattern in simulation.

The patterns of cracking and crushing in the simulation are given in Fig. 9 and Fig. 11. In comparison with the complete failure of the beam in Fig. 10. Based on the results, we can recognize that the cracking/crushing pattern using simulation is consistent with the experimental results. The damaged model used in this paper can show cracked/crushed elements that having the damaged parameters $d_{t} / d_{c}$ in range value $[0,1]$. 


\section{APPLICATION FOR SIMULATION OF A REINFORCE CONCRETE SLAB}

his example presents finite element simulations of punching shear in a concrete slab implemented by Adetifa and Polak [9]. This example is employed to evaluate the reliability of the proposed damaged model for predecting the behavior of a complex structure concrete. The geometry and details of the specimen concrete slab had the dimensions $1800 \times 1800 \times 120 \mathrm{~mm}$. For bending reinforcement, $10 \mathrm{M}$ bar were used to embed in the slab. The arrangement of bars in top layer and bottom layer is illustrated in Fig. 12. The section A-A is shown in Fig. 13 and the material characteristics are given in Tab. 3 .

(a)

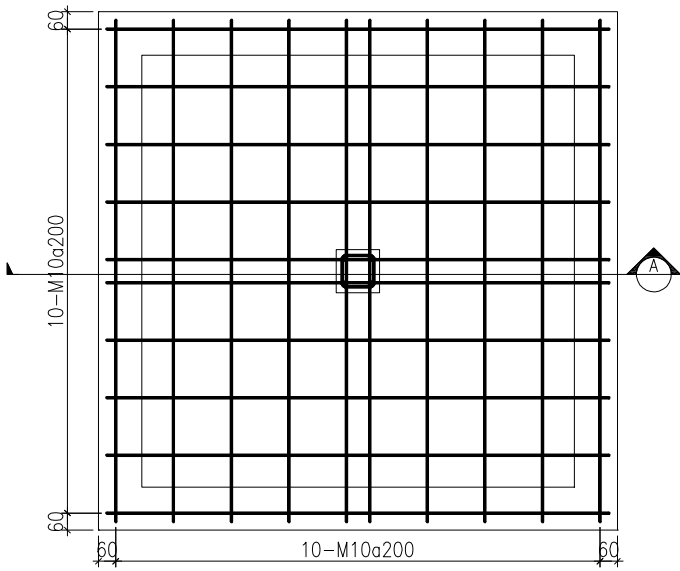

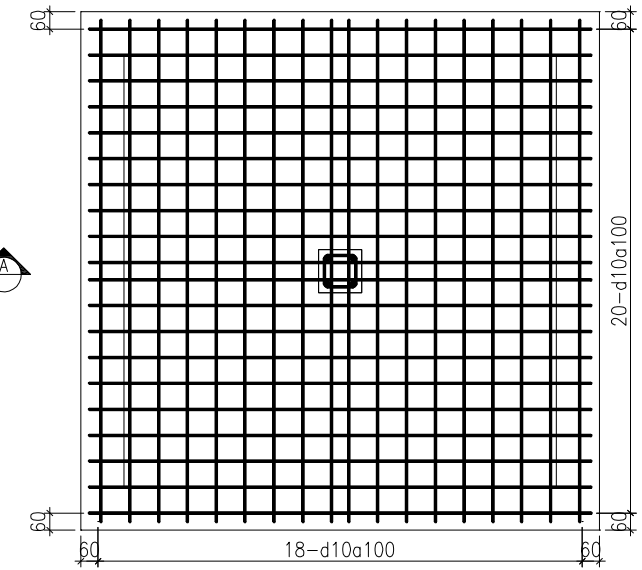

(b)

Figure 12: The arrangement of bars: (a) in the top layer, (b) in the bottom layer.

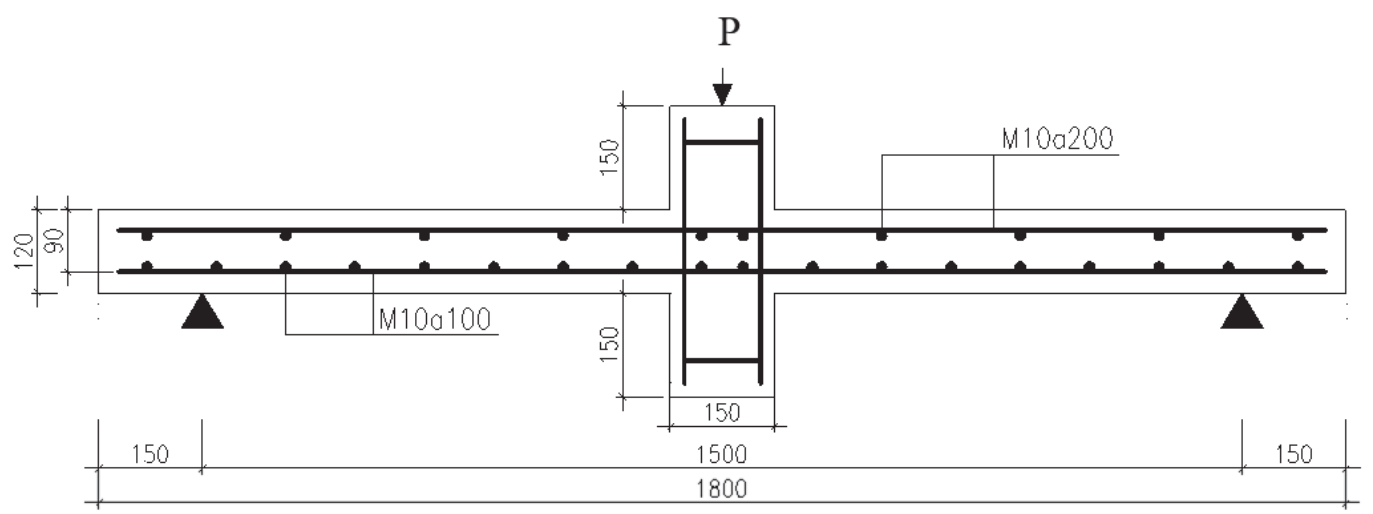

Figure 13: The section A-A of specimen.

\begin{tabular}{llll}
\hline Concrete & & & \\
Avarage compressive strength & $\mathrm{f}_{\mathrm{cm}}$ & 44 & $\mathrm{~N} / \mathrm{mm}^{2}$ \\
Modulus of elasticity & $\mathrm{E}_{\mathrm{ci}}$ & 36483 & $\mathrm{~N} / \mathrm{mm}^{2}$ \\
Rebar-d10 & & & \\
Diameter & $\phi$ & 10 & $\mathrm{~mm}$ \\
Modulus of elasticity & $\mathrm{E}$ & 200000 & $\mathrm{~N} / \mathrm{mm}^{2}$ \\
Yield strength & $\mathrm{f}_{\mathrm{y}}$ & 455 & $\mathrm{~N} / \mathrm{mm}^{2}$ \\
Ultimate tensile strength & $\mathrm{f}_{\mathrm{u}}$ & 620 & $\mathrm{~N} / \mathrm{mm}^{2}$ \\
\hline
\end{tabular}

Table 3: Material characteristics of the concrete slab. 
The process of numerical simulation using ABAQUS is carried out similar to the previous example. This process includes defining geometrical dimensions, defining the nonlinear behavior of steel and concrete materials, establishing the boundary conditions, and setting the loading process until the structure is completely damaged. The geometrical dimensions in the simulation are given in Fig. 14.
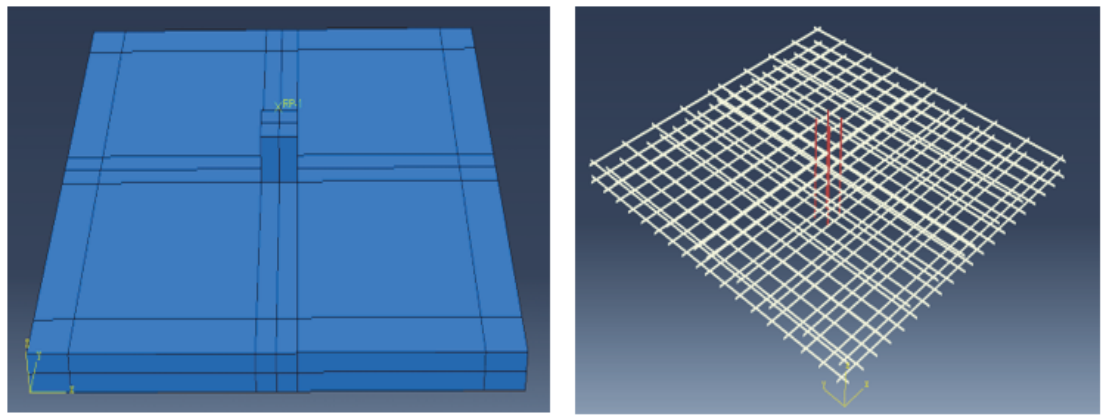

Figure 14: Simulation reinforce concrete slab using ABAQUS.

The simulation result show that the maximum punching shear force value is $243 \mathrm{kN}$ compared to the of $241 \mathrm{kN}$ obtained from experimental result. The difference between numerical simulation results and experimental results is only $0.82 \%$. The relationship between punching shear force - Displacement at the middle of slab using simulation is also very good agreement compared to experimental results as shown in Fig. 15.

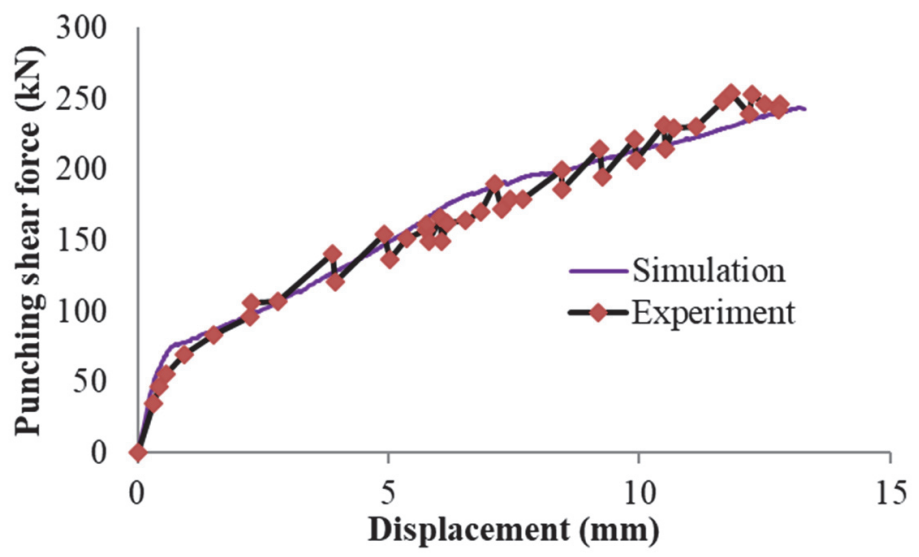

Figure 15: Comparison of displacement between simulation and experiment.

The damaged model of concrete materials using in this paper also allows to predict the crack pattern, which is defined by the elements having plastic deformation, the crack shapes in Fig. 16 and in Fig. 17 show that the position around the column with $1.5 \mathrm{~m}$ distance from the edge of the column is the crack appearing with the largest density and width.

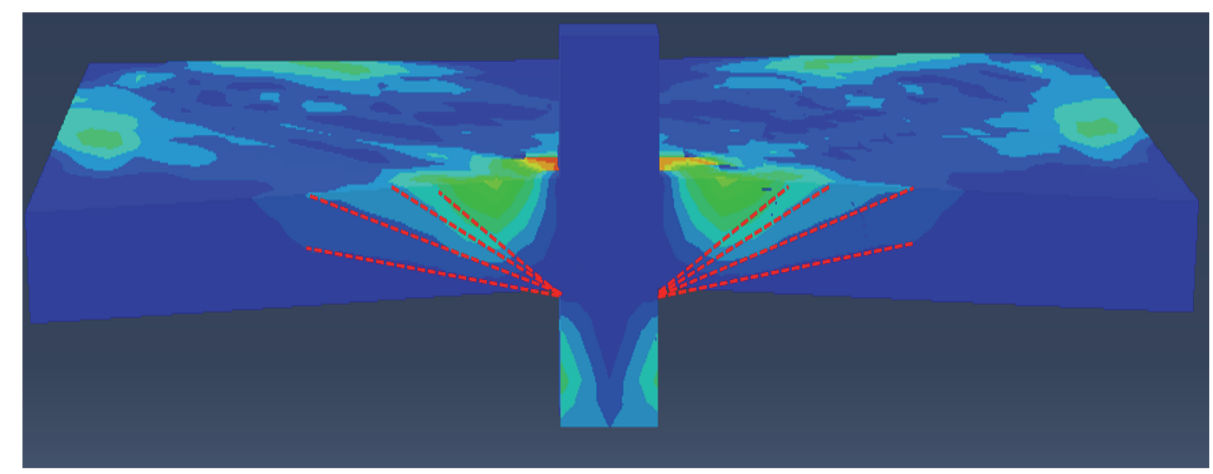

Figure 16: The damaged shape of punching shear in section view. 


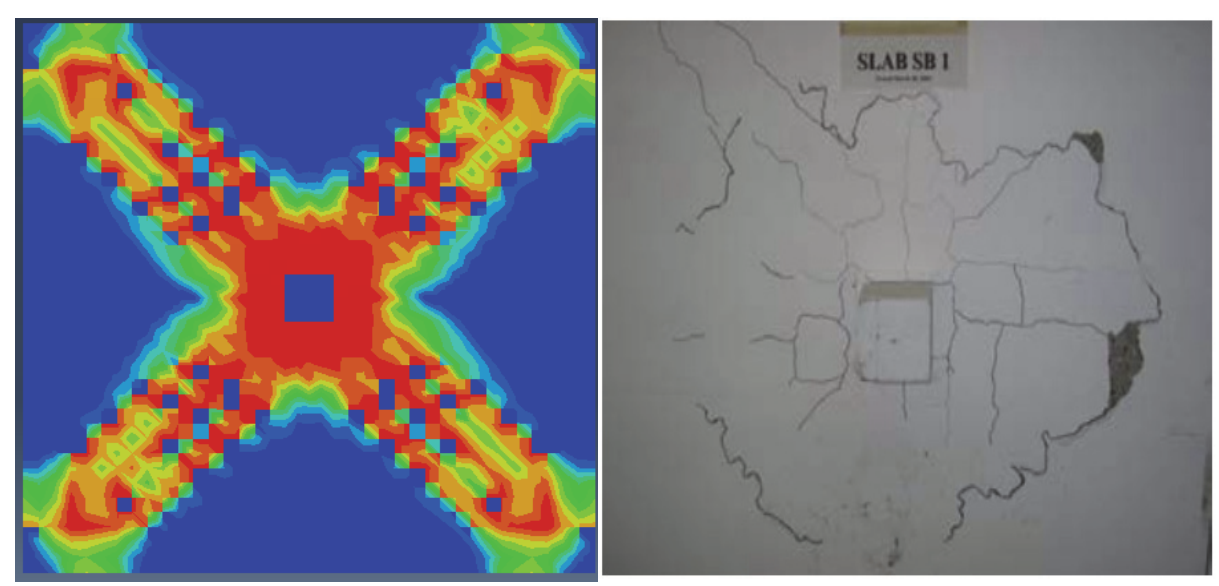

Figure 17: Comparison the crack pattern on the top of slab between simulation and experiment.

\section{CONCLUSION}

he paper presents a damaged model of concrete in numerical simulation. This model is developed lied on the CDP (available in ABAQUS) associating with the proposed damaged parameters $b_{c}=0.7$ in compression and $b_{t}=0.1$ tension. This damaged model is employed to simulate the real-test beam namely C3 in Vecchio và Shim (2004) [8] under static loading and a flat concrete slab in the test of Adetifa and Polak [9]. The numerical simulation results show that the model satisfies well with the data obtained from testing. The complete failures of the C3 beam the cracking in the top face of slab using numerical simulation illustrated that two damaged parameters responded well to the experiment's results. The model presenting in this paper can be considered as a reference model with high reliability in simulation structural reinforced concrete.

\section{ACKNOWLEDGEMENTS}

he authors gratefully acknowledge the financial support granted by the Scientific Research Fund of the Ministry of Education and Training (MOET), Vietnam (No. B2021-MBS-06).

\section{REFERENCE}

[1] Lubliner, J., Oliver, J., Oller, S. and Onate, E. (1989). A plastic-damage model for concrete. International Journal of solids and structures 25, pp. 299-326.

[2] Carol, I., Rizzi, E., Willam, K. (2001). On the formulation of anisotropic elastic degradation. II. Generalized pseudoRankine model for tensile damage, Int. J. Solids Struct., 38(4), pp. 519-546, DOI: 10.1016/S0020-7683(00)00031-7.

[3] Ahmed, B., Voyiadjis, G.Z., Park, T. (2020). Damaged plasticity model for concrete using scalar damage variables with a novel stress decomposition, Int. J. Solids Struct., 191-192, pp. 56-75, DOI: 10.1016/j.ijsolstr.2019.11.023.

[4] Lee, J., Fenves, G.L. (1998). Plastic-Damage Model for Cyclic Loading of Concrete Structures, J. Eng. Mech., 124(8), pp. 892-900, DOI: 10.1061/(asce)0733-9399(1998)124:8(892).

[5] Jason, L., Huerta, A., Pijaudier-Cabot, G., Ghavamian, S. (2006). An elastic plastic damage formulation for concrete: Application to elementary tests and comparison with an isotropic damage model, Comput. Methods Appl. Mech. Eng., 195(52), pp. 7077-7092, DOI: 10.1016/j.cma.2005.04.017.

[6] Grassl, P., Nyström, U., Rempling, R., Gylltoft, K. (2011). A damage-plasticity model for the dynamic failure of concrete, Proc. 8th Int. Conf. Struct. Dyn. EURODYN 2011, pp. 3287-3294.

[7] Birtel, V., Mark, P. (2006). Parameterised Finite Element Modelling of RC Beam Shear Failure, Ababqus User's Conf., , pp. 95-108.

[8] Vecchio, F.J., Shim, W. (2004). Experimental and Analytical Reexamination of Classic Concrete Beam Tests, J. Struct. 
Eng., 130(3), pp. 460-469, DOI: 10.1061/(asce)0733-9445(2004)130:3(460).

[9] Genikomsou, A.S., Polak, M.A. (2014). Finite element analysis of a reinforced concrete slab-column connection using ABAQUS, Struct. Congr. 2014 - Proc. 2014 Struct. Congr., , pp. 813-823, DOI: 10.1061/9780784413357.072.

[10] Engineering, S. (2015). Compressive Behavior of Unconfined and Confined Clay Brick Masonry Compressive Behavior of Unconfined and Confined Clay, October, 9445(April 2004), pp. 1562-1569,

DOI: 10.1061/(ASCE)0733-9445(2004)130. 